\title{
Effect of surface conditions on internal oxidation and nitridation of HVOF MCrAlY coatings
}

\author{
H. Chen, D.G. McCartney, K.T. Voisey \\ Faculty of Engineering, The University of Nottingham, UK.
}

\begin{abstract}
This study deals with the isothermal oxidation behaviour of high velocity oxy-fuel sprayed MCrAlY coatings. Both free-standing coatings and coatings attached to IN738 and CMSX4 substrates undergo isothermal oxidation at $1100^{\circ} \mathrm{C}$ for up to $100 \mathrm{~h}$. The effect of surface conditions (assprayed and polished) has been investigated. Scanning electron microscopy and energy dispersive $\mathrm{X}$-ray analysis were used to characterise the details of oxidation behaviour. The results have shown that both surface conditions and substrate type have a pronounced effect on oxidation behaviour. Extensive internal oxidation and nitridation is observed for polished coatings on Inconel 738 and is attributed to the combined effects of titanium diffusion from the substrate and enhanced surface diffusion due to polishing.
\end{abstract}

Keywords: HVOF; surface conditions; titanium diffusion; internal oxidation

\section{Introduction}

Thermal barrier coatings (TBCs) $[1,2]$ are used to protect turbine blades and similar components from the harsh conditions encountered in the hot gas stream. TBCs are layered structures, consisting of an outer, ceramic, layer which thermally insulates the underlying metallic component and a bond coat. As well as enhancing the adhesion of the ceramic top coat a key role of the bond coat is to provide corrosion and oxidation resistance. This is done by the generation of a protective thermally grown oxide (TGO), predominantly alumina, at the interface of the top coat and bond coat. The presence of the TGO is vital to the function of the TBC. However failure of TBCs is frequently associated with the TGO [3-5]. Ideally a TGO forms rapidly but then grows very slowly. 
It is known that the surface roughness can affect TGO growth, and that the initial TGO formed can go on to affect further TGO behaviour $[6,7]$. To maintain a protective alumina TGO an aluminium reservoir is needed within the TBC. In MCrAlY bond coats, such as those considered in this paper, a two phase, $Y / \beta$, microstructure is frequently seen, with the $\beta$ phase acting as an aluminium reservoir [8].

This paper studies the effect of substrate and surface condition on the oxidation behaviour of high velocity oxy-fuel sprayed CoNiCrAlY coatings.

\section{Experimental Methods}

All coatings included in this work were generated from a Co-31.7\% Ni20.8\%Cr-8.1\%Al-0.5\%Y feedstock powder from Praxair (CO-210-24). This had a nominal size range of $-45+20 \mu \mathrm{m}$ and a chemically analysed oxygen content of $0.037 \mathrm{wt} \% \mathrm{O}$. Spraying was carried out using a Met Jet III liquid fuel HVOF gun. Full details of the spraying process and procedures are given elsewhere [9].

The coatings were deposited onto substrates with approximate dimensions of $60 \times 25 \times 1.8 \mathrm{~mm}$. Two different superalloy substrates were used: Inconel 738 and CMSX4, with compositions as given in Figure $2 \beta$ depletion zones as a function of oxidation time for as-sprayed coatings.

Figure $3 \beta$ depletion comparison of polished coatings as a function of oxidation time.

Figure 4 Back scattered SEM micrographs showing effect of oxidation on the polished coating on Inconel 738. 
Figure 5 Internal oxidation of polished coated IN738 after $2 \mathrm{~h}$ exposure to air at $1100^{\circ} \mathrm{C}$

Figure 6 EDS mapping of near surface region of polished IN738 after $2 \mathrm{~h}$ exposure at $1100^{\circ} \mathrm{C}$

Figure 7 Titanium nitrides near the coating/substrate interface of polished coating on Inconel 738 after $100 \mathrm{~h}$ exposure at $1100{ }^{\circ} \mathrm{C}$

Table 1.

Free-standing coatings were generated by spraying onto mild steel samples to a thickness of approximately $0.5 \mathrm{~mm}$. These coatings were then debonded from the mild steel by bending around a mandrel.

The as-sprayed coatings had a surface roughness Ra value of

$6.1 \pm 0.2 \mu \mathrm{m}$, for the polished coatings the Ra decreased to

$0.2 \pm 0.1 \mu \mathrm{m}$.

Prior to oxidation all samples underwent a vacuum heat treatment for $2 \mathrm{~h}$ at $1100^{\circ} \mathrm{C}$. Samples were exposed to air at $1100^{\circ} \mathrm{C}$ for times up to $100 \mathrm{~h}$.

Sample characterisation was carried out using an SEM equipped with energy dispersive $\mathrm{x}$-ray spectroscopy.

\section{Results}

For most samples $\beta$ depletion zones were clearly seen to develop underneath an external oxide scale (Figure 8). Measured $\beta$ depletion 
zones as a function of oxidation time are shown in Figure 9 and Figure 10 for as-sprayed and polished samples respectively. It can be seen that the depletion zones for as-sprayed coatings on both substrates are very similar, and that both are notably greater than those observed for the free-standing coating (Figure 9). For the polished coatings the measured $\beta$ depletion zones for free-standing coatings and coatings on CMSX4 are all approximately twice are large as what was observed for the equivalent as-sprayed coatings. EDS analysis of the $\beta$ and $y$ phases in the assprayed coatings after $100 \mathrm{~h}$ oxidation showed the presence of titanium in the coating on Inconel 738: $0.6 \mathrm{wt} \%$ was found in the $y$ phase and $\sim 0.2 \mathrm{wt} \%$ was found in the $\beta$ phase. EDS results could not confirm the presence of $\mathrm{Ti}$ in the $100 \mathrm{~h}$ oxidised coating on the CMSX4 substrate. No results for Inconel 738 are included in Figure 10 because it was not possible to make meaningful measurements of any $\beta$ depletion zone due to the extensive internal oxidation attack seen in Figure 11. Additional phases are seen to have formed in the near surface region. The depth to which these phases extend increases with the oxidation time. This type of internal attack was only observed for the polished coatings on Inconel 738 substrates.

Results from additional, shorter term, oxidation experiments are shown in Figure 12 where the samples have been exposed for only $2 \mathrm{~h}$ but the same attack is already seen to have started. 
EDS analysis (Figure 13) reveals that the phases formed are enriched in Al, $\mathrm{O}$ and $\mathrm{N}$, with the EDS maps and compositions (Table 5) being consistent with the outermost region containing alumina the region below that containing Al rich nitrides.

For the polished coatings on Inconel 738 a third phase was noted within the coating near the coating/substrate interface after $100 \mathrm{~h}$ oxidation (Figure 14). EDS analysis of the phase was consistent with it being TiN (Table 6).

\section{Discussion}

An increased extent of $\beta$ depletion is seen for all attached coatings compared to the free-standing coatings (Figure 9 \& Figure 10). It is well known that thermal sprayed coatings contain residual stresses. On impact any molten regions of the particles solidify and then the splat cools and contracts, however the attachment to the underlying coating layers and substrate constrains this contraction. This can result in tensile stresses in the coating, with the magnitude of the tensile stresses being greatest at the outer surface. Detachment from a substrate would be expected to relieve the majority of the tensile stresses. So this means that the stress states in the free-standing and attached coatings will be different. It is suggested that the tensile stresses in the attached coatings enhance diffusion rates, thereby resulting in the observed larger depletion regions for the attached coatings compared to the free-standing coatings. 
For the coatings on CMSX4 substrates it is seen that the polished coatings have smaller $\beta$ depletion zones than the as-sprayed coatings. This can at least partially be attributed to the increased roughness, and correspondingly larger real surface area, of the as-sprayed coatings.

It is clear that the polished coatings on Inconel 738 behave very differently to all other samples. Extensive internal oxidation occurs for these coatings. This was not seen for the same type of coatings on the same substrate in the as-sprayed rather than polished condition. In addition to changing the surface roughness polishing introduces mechanical work to the surface and can thereby increase the dislocation density. Dislocations are known to act as fast diffusion paths. Polishing can therefore enhance diffusion in the surface and near surface regions. This enhanced diffusion is thought to be a contributing factor to the internal oxidation seen in the polished coatings on Inconel 738.

The polished coatings on CMSX4 were prepared in the same way so would have also undergone the same enhancement in diffusion however no internal oxidation or nitridation was seen for those coatings. The difference between these two cases is the substrate. EDS results proved that titanium from the Inconel 738 substrate diffused into the coating. Titanium is of particular interest as it has been previously reported to be able to rapidly diffuse to form TiO at a coating surface beneath the 
alumina scale [10]. CMSX4 has a significantly lower titanium content than Inconel 738, hence no titanium diffusion was expected, or observed, for coatings on CMSX4.

It is suggested that the observed extensive internal oxidation and nitridation of the polished samples on Inconel 738 is due to the combination of two factors: the enhanced diffusion due to increased dislocation density resulting from polishing and the presence of titanium. The absence of internal oxidation and nitridation in both the as-sprayed coatings on Inconel 738 and the polished coatings on CMSX4 supports the proposition that both enhanced surface diffusion and the presence of titanium are required for the observed effects to occur.

The precise role of titanium requires further study. It seems that the presence of titanium, combined with fast inward diffusion routes for oxygen and nitrogen prevent a protective alumina film from forming. It is possible that TiO forms within the coating, promoting nucleation of internal alumina. Once this internal oxidation, and nitridation, starts it continues, assisted and even accelerated by the volume expansion upon reaction [11]. However, it should be noted that no TiO was detected in this work and more detailed study is required to elucidate the precise mechanisms at work.

\section{Conclusions}

The work presented in this paper has shown that: 
- More extensive $\beta$ depletion occurred during oxidation of coatings

attached to superalloy substrates compared to free-standing

coatings.

- For attached and free-standing coatings, a larger surface roughness

produces more extensive $\beta$ depletion zones.

- For polished coatings on the, Ti rich, Inconel 738 substrate

extensive internal oxidation and nitridation occurs during oxidation.

This is attributed to the combined effects of enhanced surface

diffusion and the presence of titanium.

\section{References}

1. Evans, A.G., et al., Mechanisms controlling the durability of thermal barrier coatings. Progress in Materials Science, 2001. 46(5): p. 505-553.

2. Miller, R.A., Thermal barrier coatings for aircraft engines: History and directions. Journal of Thermal Spray Technology, 1997. 6(1): p. 35-42.

3. Rabiei, A. and A.G. Evans, Failure Mechanisms Associated with the Theramlly Grown Oxide in Plasma-Sprayed Thermal Barrier Coatings. Acta Mater, 2000. 48: p. 3963-3976.

4. Rabiei, A. and A.G. Evans, Failure mechanisms associated with the thermally grown oxide in plasma-sprayed thermal barrier coatings. Acta Materialia, 2000. 48(15): p. 3963-3976.

5. Shillington, E.A.G. and D.R. Clarke, Spalling failure of a thermal barrier coating associated with aluminum depletion in the bond-coat. Acta Materialia, 1999. 47(4): p. 1297-1305.

6. Gil, A., et al., Effect of surface condition on the oxidation behaviour of MCrA/Y coatings. Surface \& Coatings Technology, 2006. 201(7): p. 38243828.

7. Tang, F., et al., Effects of surface oxidation during HVOF processing on the primary stage oxidation of a CoNiCrAlY coating. Surface \& Coatings Technology, 2004. 185(2-3): p. 228-233.

8. Brandl, W., et al., The oxidation behaviour of sprayed MCrAlY coatings. Surface \& Coatings Technology, 1996. 86(1-3): p. 41-47.

9. Saeidi, S., in Faculty of Engineering. 2010, The University of Nottingham. 10. Krupp, U. and H.J. Christ, Internal Nitridation of Nickel-Base Alloys. Part I. Behavior of Binary and Ternary Alloys of the Ni-Cr-Al-Ti System. Oxidation of Metals, 1999. 52(3-4): p. 277-298.

11. Litz, J., A. Rahmel, and M. Schorr, SELECTIVE CARBIDE OXIDATION AND INTERNAL NITRIDATION OF THE NI-BASE SUPERALLOYS IN-738-LC AND IN-939 IN AIR. Oxidation of Metals, 1988. 30(1-2): p. 95-105. 



\section{Figure and table captions}

Figure 1 Microstructure of as-sprayed coated IN738 (top row) and coated CMSX4 (bottom row) after $100 \mathrm{~h}$ oxidation at $1100{ }^{\circ} \mathrm{C}$

Figure $2 \beta$ depletion zones as a function of oxidation time for as-sprayed coatings.

Figure $3 \beta$ depletion comparison of polished coatings as a function of oxidation time.

Figure 4 Back scattered SEM micrographs showing effect of oxidation on the polished coating on Inconel 738.

Figure 5 Internal oxidation of polished coated IN738 after $2 \mathrm{~h}$ exposure to air at $1100{ }^{\circ} \mathrm{C}$

Figure 6 EDS mapping of near surface region of polished IN738 after $2 \mathrm{~h}$ exposure at $1100^{\circ} \mathrm{C}$

Figure 7 Titanium nitrides near the coating/substrate interface of polished coating on Inconel 738 after $100 \mathrm{~h}$ exposure at $1100{ }^{\circ} \mathrm{C}$

Table 1 Nominal compositions (wt\%) of the substrates used in this work.

Table 2 EDS analysis of composition of aluminium nitrides

Table 3 EDX analysis of composition of titanium nitrides 


\section{Figures}
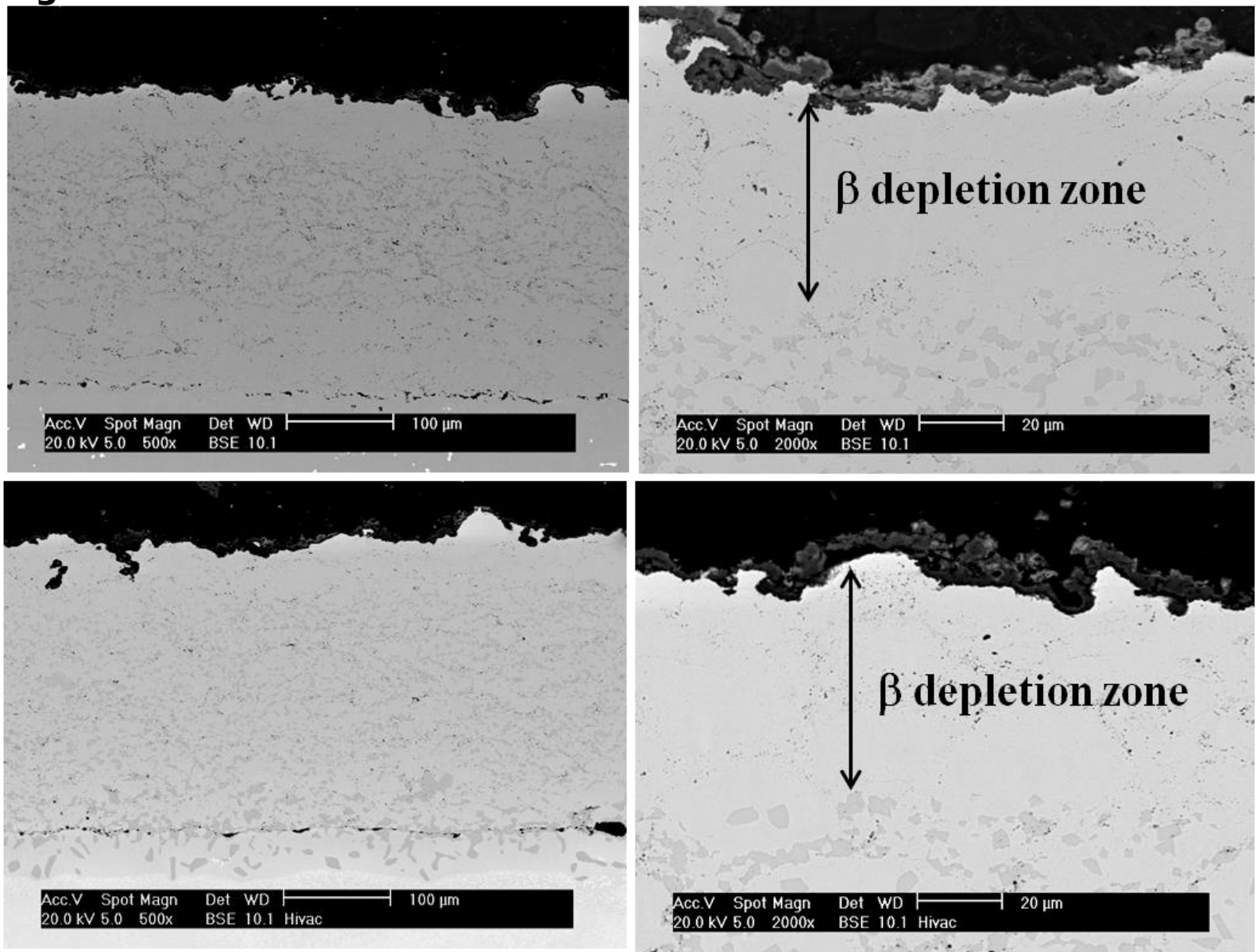

Figure 8 Microstructure of as-sprayed coated IN738 (top row) and coated CMSX4 (bottom row) after $100 \mathrm{~h}$ oxidation at $1100{ }^{\circ} \mathrm{C}$ 


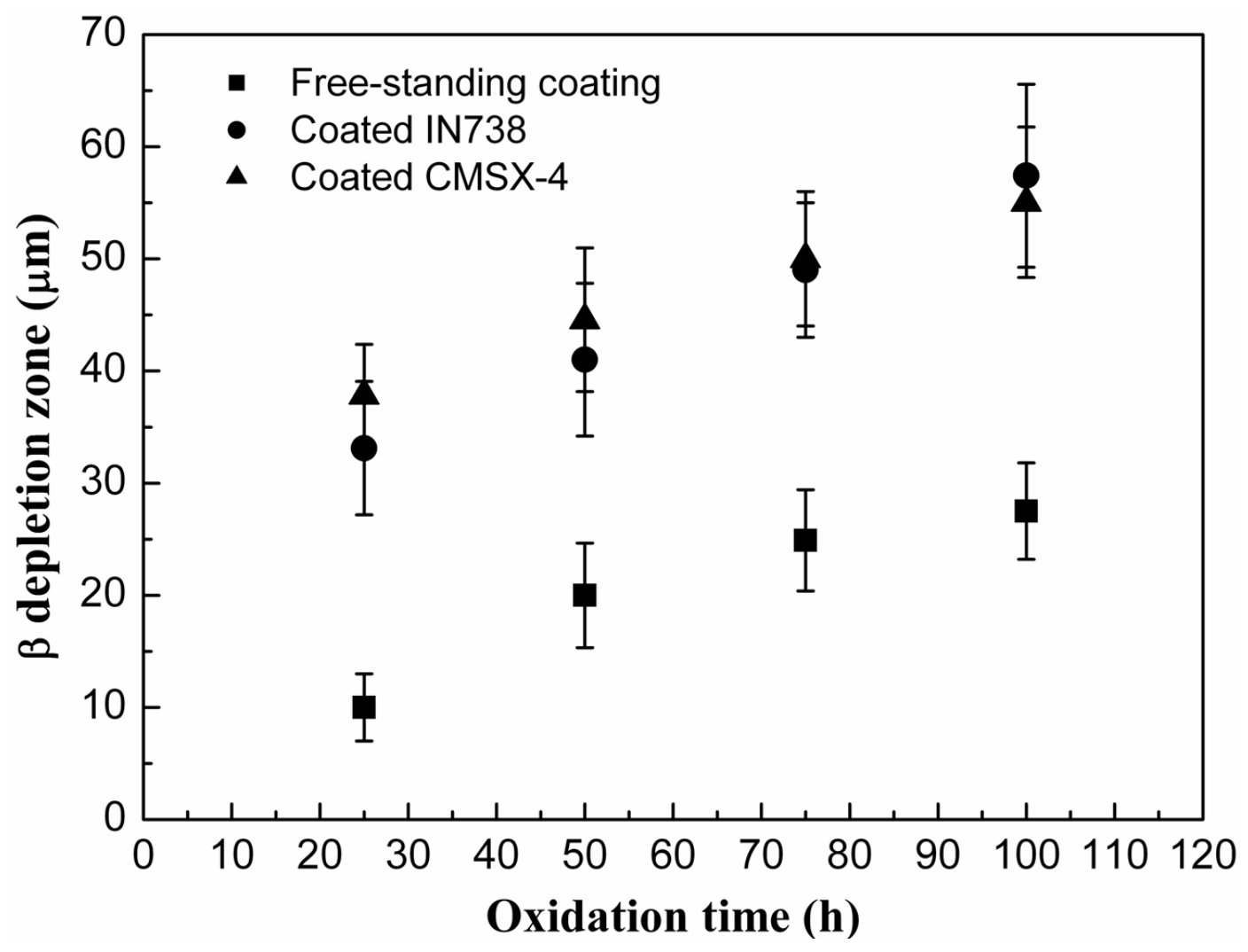

Figure $9 \beta$ depletion zones as a function of oxidation time for assprayed coatings. 


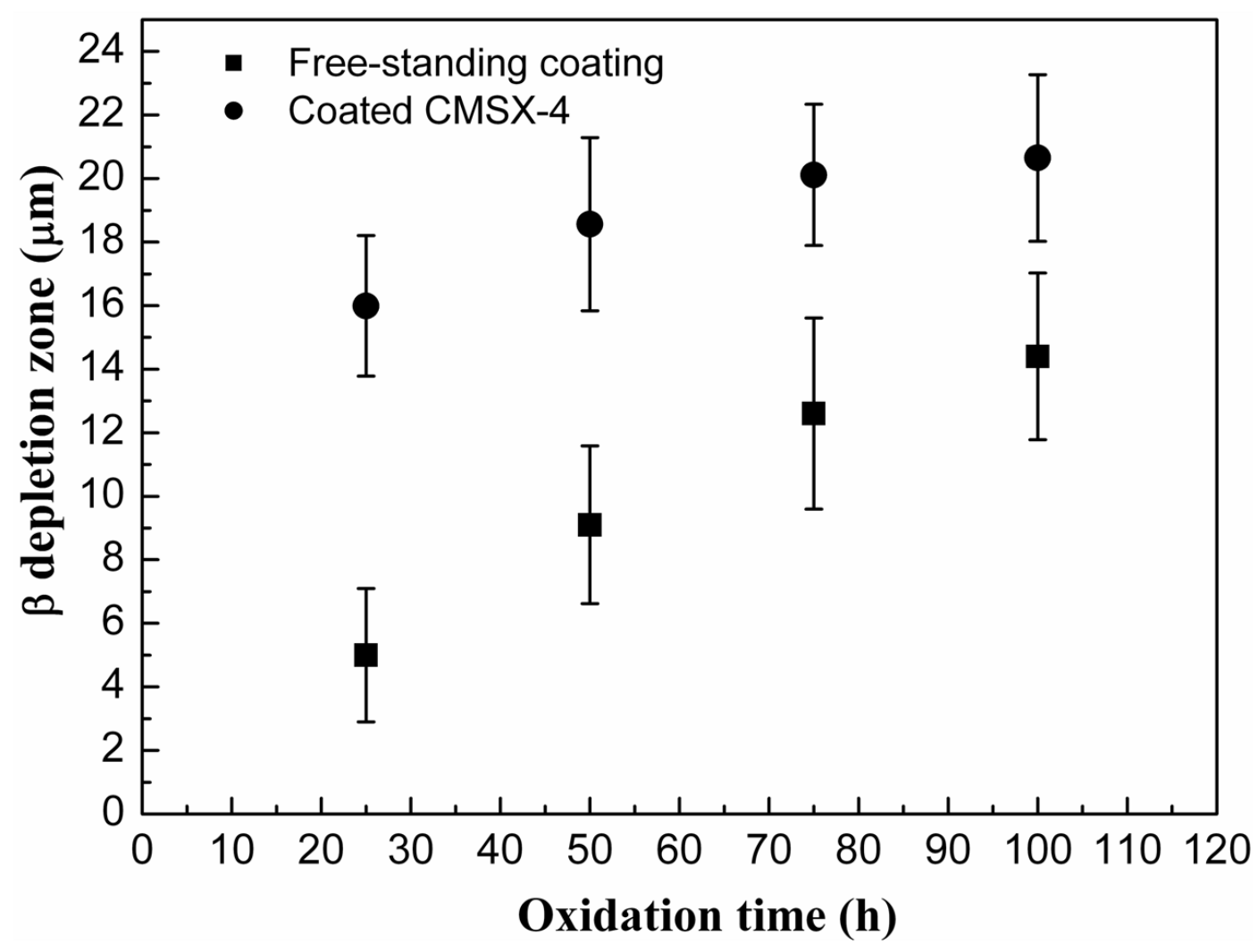

Figure $10 \beta$ depletion comparison of polished coatings as a function of oxidation time.

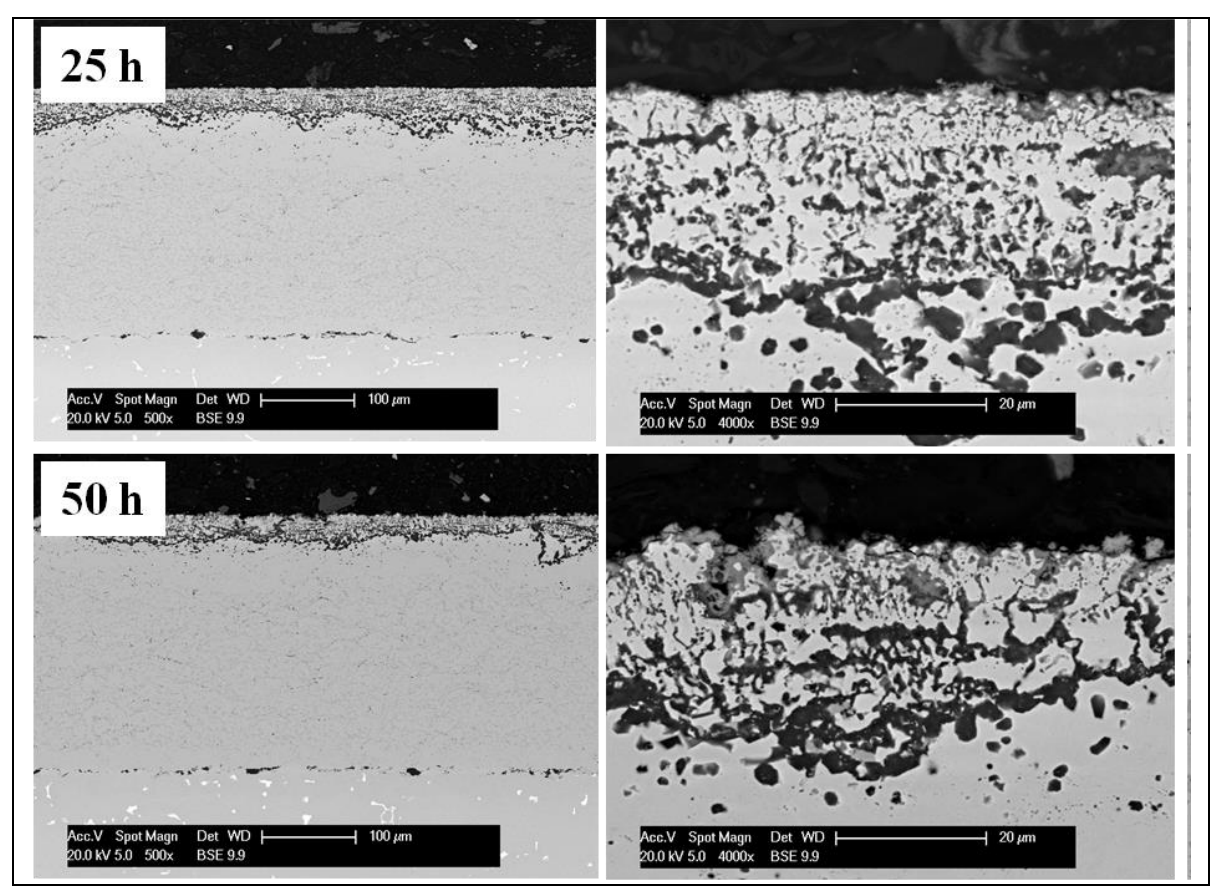




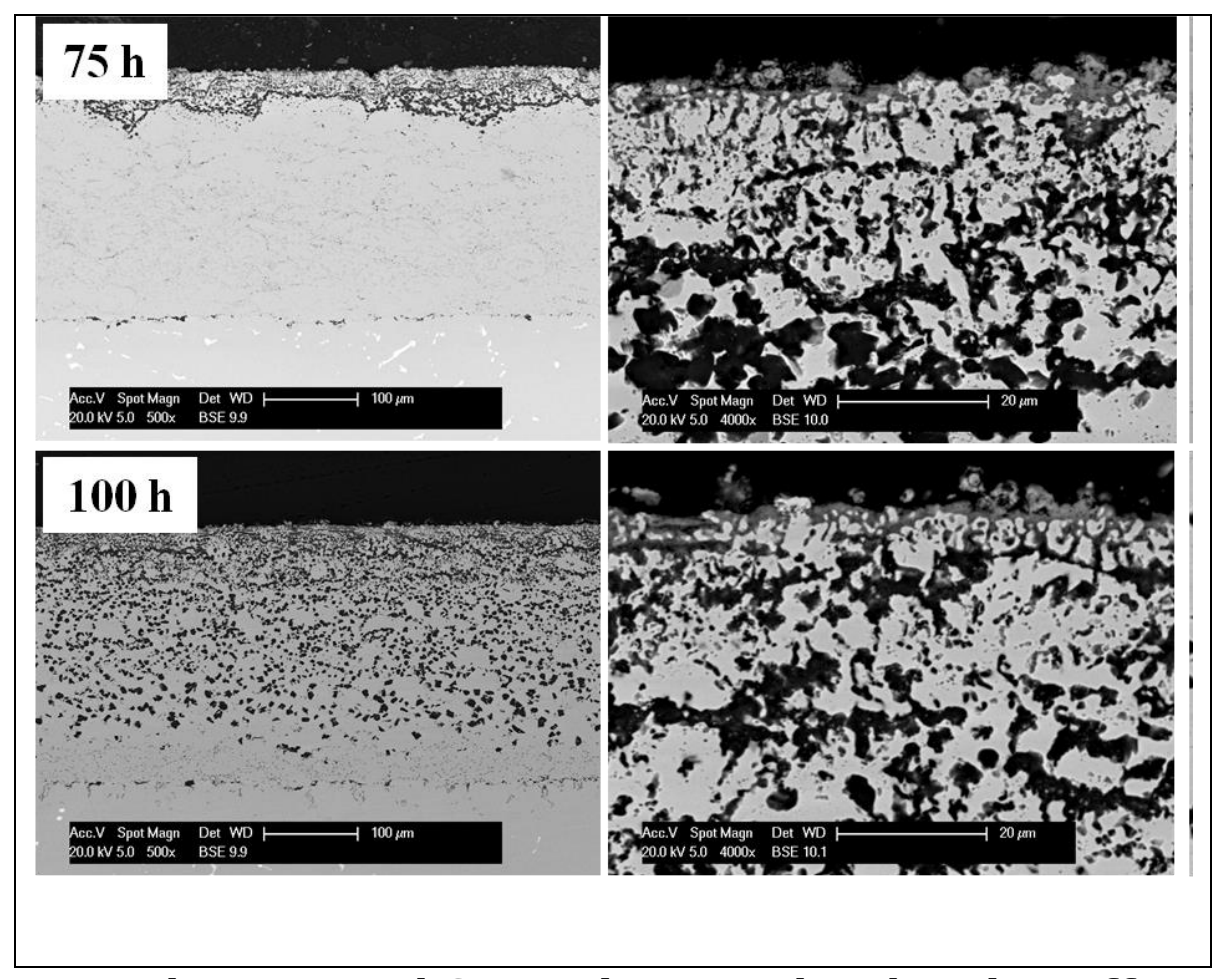

Figure 11 Back scattered SEM micrographs showing effect of oxidation on the polished coating on Inconel 738.
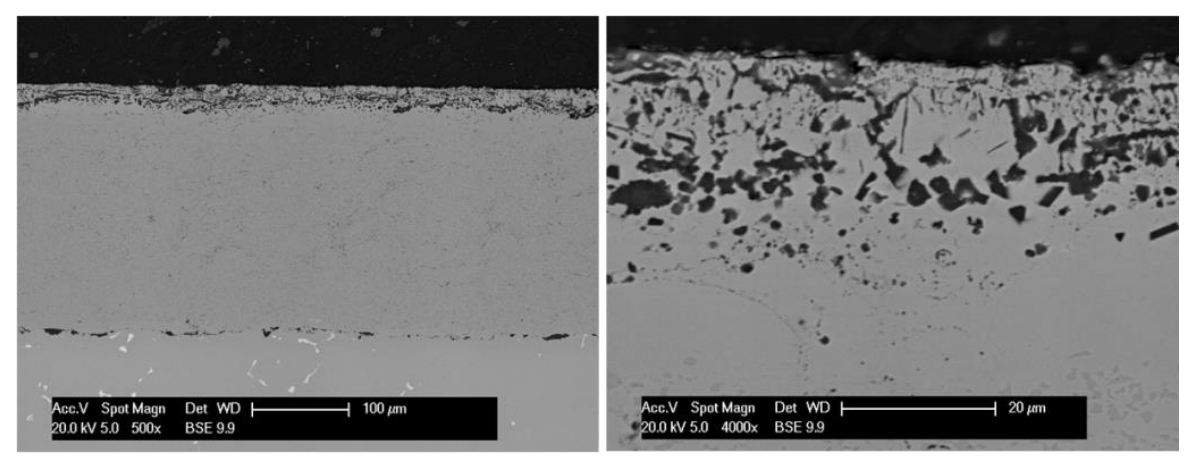

Figure 12 Internal oxidation of polished coated IN738 after $2 \mathrm{~h}$ exposure to air at $1100{ }^{\circ} \mathrm{C}$ 


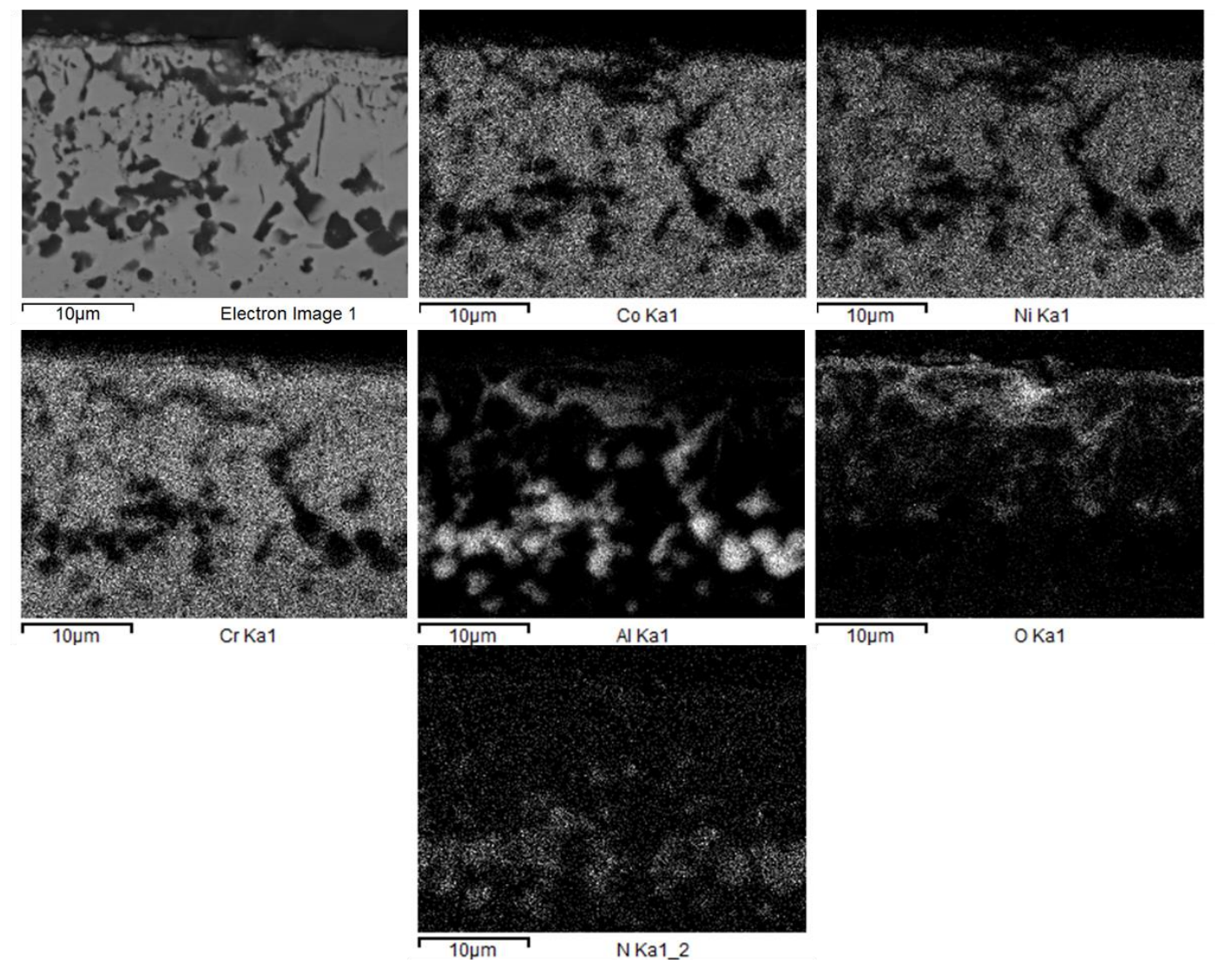

Figure 13 EDS mapping of near surface region of polished IN738 after $2 \mathrm{~h}$ exposure at $1100^{\circ} \mathrm{C}$ 


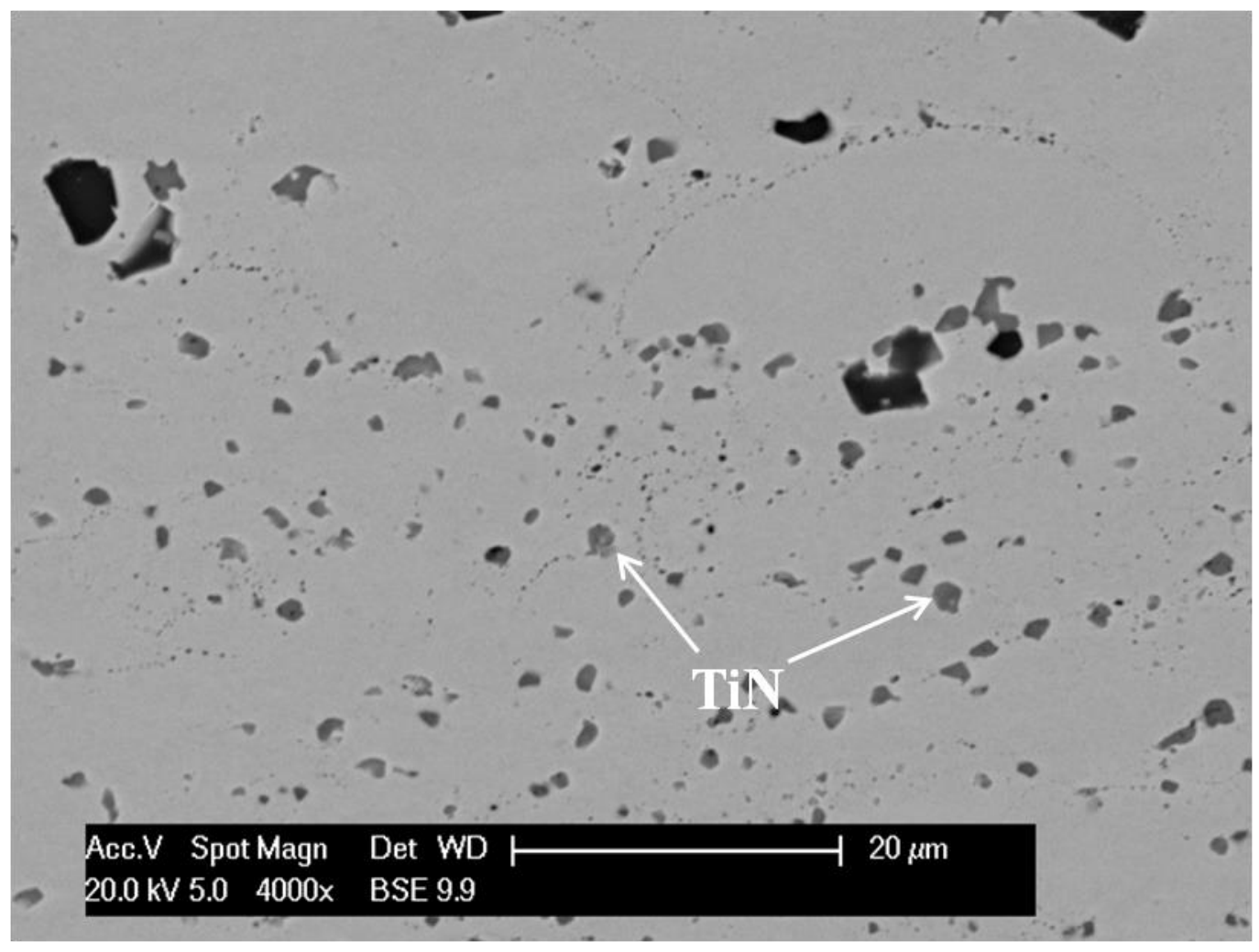

Figure 14 Titanium nitrides near the coating/substrate interface of polished coating on Inconel 738 after $100 \mathrm{~h}$ exposure at $1100{ }^{\circ} \mathrm{C}$ 


\section{Tables}

Table 4 Nominal compositions (wt\%) of the substrates used in this work.

\begin{tabular}{|c|c|c|c|c|c|c|c|c|c|c|c|c|c|c|c|}
\hline & $\mathrm{Ni}$ & $\mathrm{Cr}$ & $\begin{array}{l}\text { C } \\
0\end{array}$ & $\begin{array}{l}M \\
0\end{array}$ & $\mathrm{Al}$ & $\mathrm{Ti}$ & $\mathrm{Ta}$ & W & $\mathrm{Zr}$ & C & $B$ & $\begin{array}{l}N \\
b\end{array}$ & $\mathrm{Hf}$ & $\begin{array}{l}\mathrm{R} \\
\mathrm{e}\end{array}$ & $\begin{array}{l}\text { La+ } \\
Y\end{array}$ \\
\hline $\begin{array}{l}\text { Incon } \\
\text { el } \\
738\end{array}$ & $\begin{array}{l}\text { B } \\
\text { al }\end{array}$ & 16 & $\begin{array}{l}8 . \\
5\end{array}$ & $\begin{array}{l}1 . \\
7\end{array}$ & $\begin{array}{l}3 . \\
5\end{array}$ & $\begin{array}{l}3 . \\
5\end{array}$ & $\begin{array}{l}1 . \\
7\end{array}$ & $\begin{array}{l}2 \\
5\end{array}$ & $\begin{array}{l}0.0 \\
5\end{array}$ & $\begin{array}{l}0.0 \\
9\end{array}$ & $\begin{array}{l}0.1 \\
0\end{array}$ & 2 & & & \\
\hline $\begin{array}{l}\text { CMSX } \\
4\end{array}$ & $\begin{array}{l}\text { ba } \\
\text { l }\end{array}$ & $\begin{array}{l}6 . \\
5\end{array}$ & 9 & $\begin{array}{l}0 . \\
6\end{array}$ & $\begin{array}{l}5 . \\
6\end{array}$ & 1 & $\begin{array}{l}6 . \\
5\end{array}$ & 6 & & & & & $\begin{array}{l}0 . \\
1\end{array}$ & 3 & $\begin{array}{l}0.00 \\
2\end{array}$ \\
\hline
\end{tabular}

Table 5 EDS analysis of composition of aluminium nitrides

\begin{tabular}{c|c|c|c|c|c}
\hline AIN & Co & $\mathrm{Ni}$ & $\mathrm{Cr}$ & $\mathrm{Al}$ & $\mathrm{N}$ \\
\hline $\mathrm{wt} \%$ & $1.5 \pm 0.3$ & $1.6 \pm 0.8$ & $1.0 \pm 0.5$ & $62.3 \pm 0.3$ & $33.6 \pm 0.7$ \\
\hline at\% & $0.6 \pm 0.2$ & $0.6 \pm 0.3$ & $0.4 \pm 0.2$ & $49.6 \pm 1.3$ & $48.6 \pm 1.6$ \\
\hline
\end{tabular}

Table 6 EDX analysis of composition of titanium nitrides

\begin{tabular}{c|c|c|c|c|c|c}
\hline TiN & Co & $\mathrm{Ni}$ & $\mathrm{Cr}$ & $\mathrm{Al}$ & $\mathrm{N}$ & $\mathrm{Ti}$ \\
\hline $\mathrm{wt} \%$ & $12.7 \pm 2.4$ & $\begin{array}{c}16.5 \\
\pm 2.8\end{array}$ & $9.4 \pm 1.3$ & $<1$ & $15.5 \pm 1.2$ & $45.7 \pm 3.2$ \\
\hline at\% & $7.4 \pm 0.6$ & $9.8 \pm 1.7$ & $6.5 \pm 0.8$ & $<1$ & $48.6 \pm 1.6$ & $33.4 \pm 3.9$ \\
\hline
\end{tabular}

